\title{
An Evidence-Based Strategic Approach to Prevention and Treatment of Dry Eye Disease, a Modern Global Epidemic
}

\author{
Pragnya R. Donthineni ${ }^{1}$, Swapna S. Shanbhag ${ }^{1}$ and Sayan Basu ${ }^{1,2, *}$ \\ 1 The Cornea Institute, L V Prasad Eye Institute, Hyderabad 500034, India; drpragnyarao@lvpei.org (P.R.D.); \\ swapnashanbhag@lvpei.org (S.S.S.) \\ 2 Center for Ocular Regeneration (CORE), L V Prasad Eye Institute, Hyderabad 500034, India \\ * Correspondence: sayanbasu@lvpei.org; Tel.: +91-040-30612555
}

Citation: Donthineni, P.R.; Shanbhag, S.S.; Basu, S. An Evidence-Based Strategic Approach to Prevention and Treatment of Dry Eye Disease, a Modern Global Epidemic. Healthcare 2021, 9, 89. https://doi.org/10.3390/ healthcare 9010089

Received: 9 December 2020 Accepted: 12 January 2021 Published: 17 January 2021

Publisher's Note: MDPI stays neutral with regard to jurisdictional clai$\mathrm{ms}$ in published maps and institutional affiliations.

Copyright: (C) 2021 by the authors. Licensee MDPI, Basel, Switzerland. This article is an open access article distributed under the terms and conditions of the Creative Commons Attribution (CC BY) license (https:// creativecommons.org/licenses/by/ $4.0 /)$.
Abstract: Dry eye disease (DED) is an emerging health concern causing significant visual, psychological, social, and economic impact globally. In contrast to visual rehabilitation undertaken at late stages of DED, measures instituted to prevent its onset, establishment, or progression can alter its natural course and effectively bring down the associated morbidity. This review attempts to present the available literature on preventive strategies of DED at one place, including strategies for risk assessment and mitigation, targeting a wide range of population. A literature search was conducted using PubMed and an extensive literature review on preventive strategies for DED was compiled to put forth a holistic and strategic approach for preventing DED. This can be undertaken at various stages or severity of DED directed at different tiers of the health care system. Conclusion: This review intends to put emphasis on preventive strategies being adopted as an integral part of routine clinical practice by general ophthalmologists and specialists to tackle the burden of DED and improve the quality of the lives of the patients suffering from it.

Keywords: dry eye; prevention; levels of prevention; dry eye disease; tiers of prevention; computer vision syndrome

\section{Introduction}

Dry eye disease (DED) is a multifactorial disease caused by a vicious cycle of dysregulated ocular inflammation leading to chronic ocular surface dysfunction [1]. The prevalence of DED has been increasing globally among all age groups, with escalating rates being reported among children and adolescents [2,3]. The emergence of a digital revolution and increasing dependence on video display units (VDUs) further elevates the risk of DED [4]. While patients with pre-existing disease continue to suffer owing to its chronic clinical course, the addition of new cases with time will only increase the overall disease burden. The end-stage ocular surface disease resulting from chronic and advanced DED is exceptionally challenging to manage and has substantial cost implications [5]. Apart from causing significant ocular morbidity, DED can commonly be associated with underlying systemic autoimmune pathologies that could potentially be life-threatening. These patients also experience role limitation, pain, and poor general health, significantly impacting their quality of life (QoL) comparable to the QoL for serious debilitating medical illnesses such as chronic kidney disease and severe angina [6]. Additionally, DED has also been associated with anxiety, depression, and sleep disorders and can have a great deal of economic, social, and psychological impact on the individual suffering from it [6,7].

With the ongoing epidemiological transition, there is a shift in disease patterns from communicable illnesses such as infections to the dominance of non-communicable chronic diseases. Recent epidemiological studies have estimated that the annual incidence and prevalence of DED would continue to rise significantly in the coming years $[8,9]$. This becomes even more pertinent during situations such as the global COVID-19 pandemic, 
where person-to-person interactions are being minimized at the cost of increased dependence on technology and VDUs. Thus, the belief that "an ounce of prevention is worth a pound of cure" is extremely relevant in the current times. It is, therefore, essential for treating physicians to acknowledge that the effect of treatment in controlling a disease is unsustainable without having appropriate preventive strategies in place. Thus, while we continue to focus on effectively treating patients with DED, it is crucial to direct efforts towards establishing preventive strategies to bring down the overall impact of the disease. These include primordial prevention intercepting emergence of risk factors, primary prevention to prevent the onset of the disease, secondary prevention aiming at early diagnosis and treatment and tertiary prevention to limit complications and visually rehabilitate patients with DED. Thus, in this review, the authors aimed to discuss an integrative approach to manage DED that emphasizes on preventive and promotive strategies at various levels of health care.

\section{Methods and Literature Review}

In August 2020, the literature searches pertaining to the components of this review were completed using PubMed. The keywords used for the study were "dry eye," "dry eye disease," "computer vision syndrome," "digital eye strain," "video terminal users," "office ergonomics training," and "prevention of dry eye." As the volume of literature recovered was huge, we included only articles in the English language that had relevance with primordial, primary, secondary, tertiary, or quaternary prevention of DED. This significantly narrowed down our search, and the final articles were included for the current literature review.

\section{Levels of Prevention of DED}

One of the best aspects of healthcare reforms is the emphasis laid on the prevention of disease. While we clinicians strive to excel in treating a manifested illness, there is a pressing need to advance equally the prevention of its establishment and progression. In order to achieve this, measures should be directed at various tiers of prevention (Figure 1) [10]. Like any other disease, the strategies to prevent DED can be classified into the following five levels:

1. Primordial prevention;

2. Primary prevention;

3. Secondary prevention;

4. Tertiary prevention;

5. Quaternary prevention.

\subsection{Primordial Prevention of DED}

This tier of prevention includes measures that can avoid the emergence and establishment of social, cultural, and economic patterns of living that can elevate the risk of DED [10]. Thus, for primordial prevention, we need to target the general population as a whole to prevent the emergence of risk factors of DED. 


\section{LEVELS OF PREVENTION OF DRY EYE}

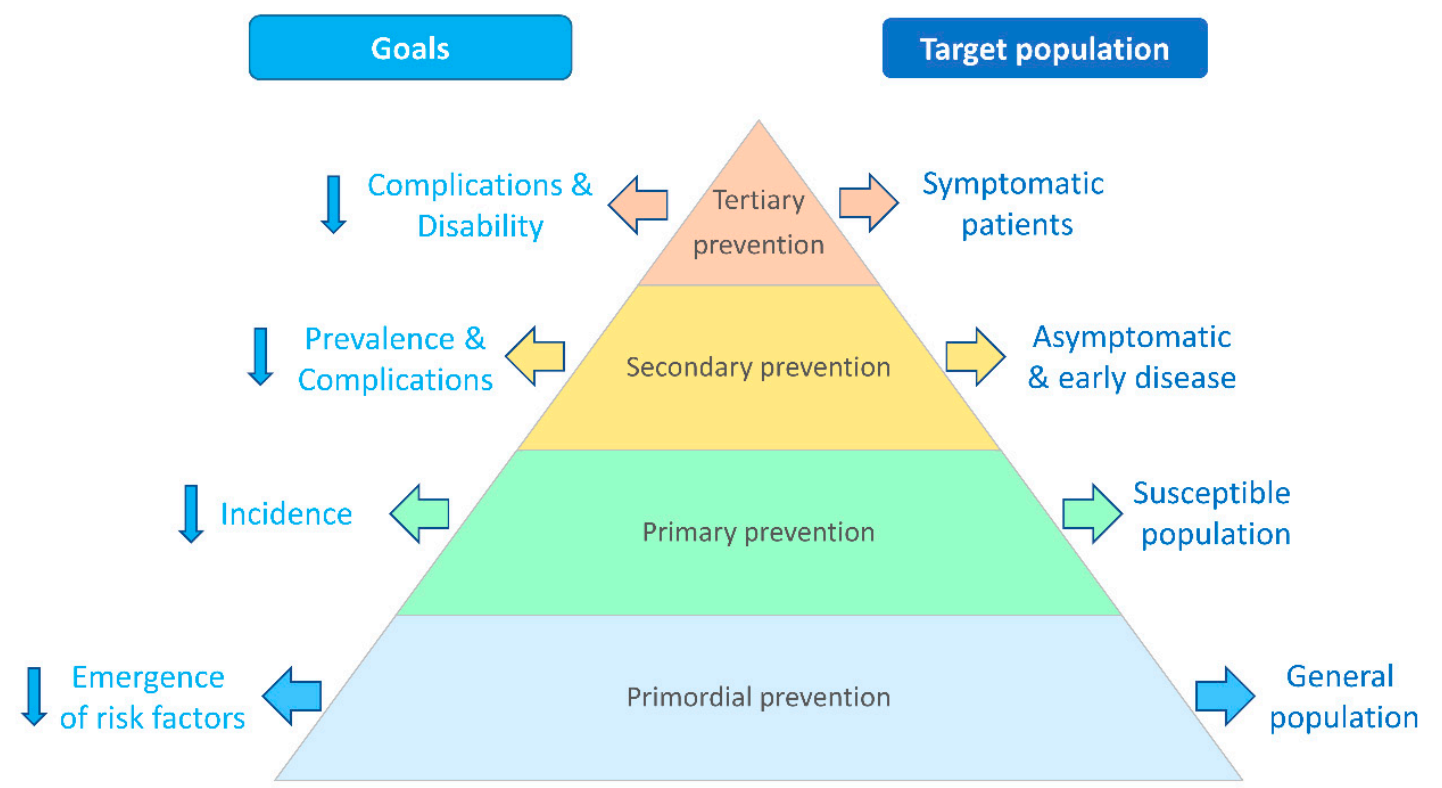

Figure 1. Tiers of prevention of dry eye disease (DED): this figure describes the pyramid depicting the preventive strategies at various levels of health care with the goals (arrows on the left) and the target population (arrows on the right).

\subsubsection{Strategies for Primordial Prevention}

Epidemiological Research

Epidemiological research is of paramount importance to identify the various risk factors of DED. Identifying underlying conditions that can lead to exposure to causative factors can go a long way in addressing this disease at its grassroots. Numerous epidemiological studies have reported age, sex, place of residence, urbanization, occupation, and socio-economic status as significant risk factors for developing DED [9]. Increased risk of DED has also been associated with prolonged exposure to sunlight, indoor smoke, and smoking [11]. With growing urbanization and digitization, along with dynamically changing environmental exposures, we can anticipate a greater surge in cases of DED in the coming years. Epidemiological research can thus help healthcare agencies in policymaking to establish comprehensive public healthcare measures to tackle this emerging disease.

\section{Lifestyle Modifications}

Lifestyle changes such as increased use of VDU's, sedentary lifestyle, and a diet deficient in Vitamin A, Vitamin D, or Omega-3 fatty acids could contribute to the emergence of DED [12-14]. Vitamin A deficiency continues to significantly cause DED among children in developing countries, despite being preventable [15]. The resulting dryness in Vitamin A deficiency is due to either lacrimal insufficiency or poor surface wettability caused by altered glycocalyx and reduced goblet cells [16]. Vitamin D is known to decrease ocular surface inflammation and improve the tear film osmolarity, stability, and corneal epithelial barrier function [17]. Hwang et al. reported that Vitamin D improved the efficacy of lipidbased topical lubricants when it was administered as adjuvant therapy in patients with DED [18]. This could be due to the augmented production of ocular surface surfactants that enhance the miscibility of lipid-based formulations into the aqueous layer of the tear film. Thus, dietary supplementation with Vitamin A and D and behavioral changes such as a reduction in screen time and increased physical activity can help modify healthdamaging exposures if promoted from childhood $[19,20]$. A few short-term studies reported a positive role of Omega-3 fatty acid supplementation in treating DED [21,22]. However, the dry eye assessment and management (DREAM) study revealed that Omega-3 fatty acid 
supplementation offered no additional long-term benefit over placebo in alleviating the symptoms. Its extension withdrawal study also reported results consistent with the former study $[23,24]$.

\section{Health Education}

Health education promoting ocular surface protective measures can be undertaken among the general population, especially targeting children, adolescents, and other highrisk groups [3,25]. Conducting workshops to impart skill transfer to modify lifestyle and workplace ergonomics can be beneficial. Utilizing mass media for health education in the community can help create a conducive ecosystem where health-related measures could become a new normal [25].

\section{Genetic Screening}

DED can also be caused by rare inherited diseases, such as anhidrotic ectodermal dysplasia, epidermolysis bullosa, Riley Day syndrome, Ichthyosis, and congenital alacrimia, and their associations, such as Allgrove or Triple-A syndrome, lacrimal-auriculo-dentodigital (LADD) syndrome, and Pierre Robin sequence. Genetic screening of the population at risk, though expensive, can prove to be helpful in such scenarios [17].

\section{Legislative Regulations and National Policies}

Most countries across the globe have work related regulations governed by legislature, to improve productivity while ensuring safety of the working class. Thus, having work hour restrictions for individuals exposed to prolonged screen time can help reduce the risk of DED in this specific group. Occupational exposure to chemicals and industrial accidents can also cause DED [26]. The risk of exposure to such occupational hazards can be mitigated by having mandatory protective measures for individuals at high risk for ocular chemical, thermal, or radiation injuries. Environmental pollution and particulate matter exposure have also been associated with DED and can be effectively addressed only when the countermeasures are planned as legislative policies to conserve the environment [11,27].

\subsection{Primary Prevention}

This level of prevention includes measures taken to prevent the onset of disease by controlling the causes and risk factors and targeting the susceptible population. Interventions can be applied before there is any evidence of disease to bring down the overall incidence of DED [10]. This can be achieved by using population strategy, individual high-risk strategy, or a combination of both. In population strategy, attention is focused on the entire population to reduce the average risk of disease, whereas in the individual high-risk strategy, individuals vulnerable to disease-specific exposure are targeted [10].

\subsubsection{Strategies for Primary Prevention}

Screening for the Presence of Risk Factors

Identifying risk factors for developing DED among individuals is the most crucial aspect of this tier of prevention. Screening the general population for risk factors for DED with a particular focus on high-risk groups, such as those in the geriatric age group, perimenopausal women, contact lens users, or those with long-term use of systemic and topical medications, can be helpful [28]. Common ocular conditions, such as meibomitis and demodex blepharitis have been associated with developing DED, which need to be looked for in all patients presenting to the clinics [17]. Individuals with increased screen time, such as software professionals and adolescents, are also at high risk for developing DED [12]. Prolonged exposure to VDUs is associated with a reduction in the blink rate by 40-60\% and an incomplete blink amplitude as compared to normal individuals [29-31]. This could contribute to the rapid desiccation of the tear film, causing ocular fatigue and subsequent development of computer vision syndrome (CVS) [32]. 


\section{Minimizing Iatrogenic DED}

Iatrogenic dry eye disease is known to be caused by contact lens wear, long term use of topical and systemic medications, and interventions such as corneal refractive surgery, keratoplasty, cataract, and lid-related surgeries [28]. Various medications with anticholinergic activity, such as anti-depressants, neuroleptics, antihistamines, and anti-hypertensives, have been associated with DED [28]. This action is attributed to the involvement of Gprotein coupled $\mathrm{M}$ (muscarinic) receptors in the lacrimal gland acini and conjunctival goblet cells, leading to aqueous and mucin deficiency and subsequent DED [28]. On the other hand, adrenergic agonists, such as beta-blockers and alpha agonists, can also alter tear film volume and quality via the protein kinase $C$ pathway [33]. Thus, once an iatrogenic risk factor is identified by screening, various strategies for risk mitigation can be undertaken to prevent the onset of DED in the future.

\section{Health Education}

Imparting education to increase the knowledge and awareness of early signs and symptoms of DED among high-risk groups can be instrumental in disease prevention. Enabling these patients to detect symptoms early by themselves during the disease course can translate into effective preventive practice. Numerous crowd-sourced cross-sectional studies using smartphone applications have identified individuals with undiagnosed and diagnosed DED and its associations, such as clinical depression [34]. Additionally, training individuals with prolonged VDU to adopt office ergonomic practices has helped improve visual symptoms and increase work productivity [35].

\section{Workplace Ergonomics and Modifications}

The work environment can play an essential role in developing and perpetuating the vicious cycle of DED. Factors such as low humidity, air pollution, screen brightness, and ambient light among VDU users have been associated with the risk of developing DED and reduced work performance [36]. Thus, appropriate work environment modifications can alleviate these negative influences and increase work performance. Recommended improvements include an appropriate location of the screens, with eyes looking downward by $15-20$ degrees and $60-100 \mathrm{~cm}$ away while working $[37,38]$. Other recommendations include reducing the level of screen brightness by using screen guards and blue filters [35], reducing glare from ambient light by using blinds and screens over windows and light sources [28], and maintaining a proper body posture with well-adjusted chair height and wrist support while typing [32].

\section{Eye Protective Health Practices during VDU Use}

Measures protecting ocular health while using VDUs can include refractive error correction, taking frequent breaks once every 20-30 min, preferably by looking at a distant object [39], blinking at regular intervals, and using protective eyewear with anti-glare tinting [40]. Various software applications facilitating users to set reminders that prompt them to blink and stretch the body at regular intervals have reported being useful [41].

\section{Micronutrients and Nutraceutical Supplementation}

Supplementation of micronutrients and nutraceuticals can prove to be useful in individuals susceptible to developing DED [42]. This can be achieved either by recommending dietary changes or by prescribing nutraceuticals. Dietary nutraceuticals are concentrated or the purified form of the micronutrients, such as antioxidants, omega- 3 fatty acids, and multivitamins, are extracted from food products and administered as medicinal formulations. Antioxidant complex supplementation (including beta-carotene, ascorbic acid, Vitamin B, E, Zinc, and copper), when administered in a crossover placebo-controlled, double-masked randomized control trial, has demonstrated improvement of tear film stability, squamous metaplasia, and goblet cell density without significant change in tear volume [43]. Though some benefit has been demonstrated in the literature, more research 
needs to be carried out to look at the accurate composition, dosage, and indications of nutraceutical supplementation $[43,44]$.

\subsection{Secondary Prevention}

This level of prevention aims at early detection and early treatment of DED. Interventions are more effective in the early stages where there is a window of opportunity to either reverse the disease or halt its progression. Thus, targeting patients with asymptomatic and early disease can reduce the prevalence of DED and prevent the morbidity associated with it.

\subsubsection{Strategies for Secondary Prevention Screening for the Presence of DED}

Recognizing the presence of risk factors among patients and having a low index of suspicion can help identify asymptomatic patients in the early stage of DED. Screening the patients at risk, such as those with meibomitis, diabetes, autoimmune diseases, contact lens use, prolonged VDT use, or long-term use of topical or systemic medications associated with DED, can help with early diagnosis. Tear film osmolarity is superior to questionnaires like ocular surface disease index (OSDI )as a more reliable screening tool to detect ocular surface alterations, as studied in individuals with prolonged VDT use [45].

\section{General Health Measures}

Health measures, such as whole-body hydration, lid scrubs, lid massage, warm compresses, and use of topical lubricants, are measures that can easily be followed by all patients of DED [46]. The use of eye guards and humidifiers at home and in the workplace can prevent disease progression among office workers $[39,47,48]$. Isolation of the ocular surface by using microenvironment glasses (MEGS) in combination with the use of artificial tears and environmental manipulations is reported to be most effective in treating patients with CVS. Moist, cool air devices have also been reported to alleviate dry eye symptoms and improve tear film stability, especially among prolonged VDT users [49].

\section{Medical Therapy}

The options for medical therapy of DED are vast beyond just the use of topical lubricants, which is considered the traditional line of management. Numerous formulations of preservative-free artificial tears are available with variable combinations of aqueous base and viscosity enhancers that are safe and effective in treating mild to moderate DED [50]. Apart from lubricants, topical treatment with either $0.5 \%$ Loteprednol etabonate or $1 \%$ Methylprednisolone for induction and maintenance with topical cyclosporine provided faster symptomatic relief clinical improvement of the ocular surface that can limit associated keratopathy [51,52]. Newer osmoprotectants, such as Trehalose, can protect the ocular surface from desiccation, apoptosis, and oxidative stress and maintain corneal epithelial homeostasis, which could be invaluable if initiated in the early stages of DED [53]. Lipid-based preparations or emulsions have been gaining popularity and are reported to be useful, especially in MGD and lipid layer deficiency, as they address the root cause of poor lipid layer quality [54]. Other newer drugs, such as topical secretagogues, are also being explored in the treatment of DED. Diquafosol tetrasodium, a purinergic P2Y2 receptor agonist, is one such drug that has been reported to stimulate mucin from conjunctival epithelium and goblet cells [55]. Another mucin secretagogue, Rebamipide, has shown promising results with improvement in subjective symptoms, tear film breakup time (TBUT), lissamine conjunctival staining, and corneal fluorescein staining following therapy [56]. Furthermore, it has also been effective in treating lid wiper epitheliopathy and short TBUT DED [57]. Lifitegrast, a newer integrin antagonist, has shown a reduction in $\mathrm{T}$ cell migration, recruitment, and cytokine release having a potential application in therapy of DED [58]. Timely and prompt initiation of appropriate treatment in the early 
stages of DED, targeting inflammation and component deficiency, can limit keratopathy and minimize complications.

Surgical Management

Though surgical management is not always required in asymptomatic and early stages of DED, some minor procedures have been found to be beneficial in limiting ongoing damage due to the chronic course of DED. Enhancement of aqueous retention by techniques causing temporary or permanent punctal occlusion can help improve the symptoms of DED. This could be achieved by either placing absorbable or non-absorbable punctal plugs or by surgical punctal occlusion [59]. Surgical punctal occlusion can generally be achieved by using partial or total thermal punctal cauterization, sutured punctal pugs [59], conjunctival flap or graft placement over the punctum [60], extirpation of the canaliculus, or canalicular ligation [61]. These procedures come with their own set of risks and benefits and need to be performed judiciously only when indicated [59].

\subsection{Tertiary Prevention}

In this level of prevention, interventions are designed to arrest the progression of an established disease, and thereby, control the complications among symptomatic patients [10]. The primary aim is to minimize the associated disability and suffering. This is the most taxing among all the preventive tiers of the health care system due to the long-term management of chronic disease involved and the substantial cost of surgery and rehabilitation [5]. Though tertiary prevention incurs higher costs while catering to smaller populations, most ophthalmologists, unfortunately, limit their preventive practice to only this level of prevention.

\subsubsection{Measures for Tertiary Prevention}

Diagnosis of Underlying Systemic Associations

DED is commonly associated with underlying systemic diseases, such as connective tissue disorders and autoimmune bullous diseases, that are often both sight- and lifethreatening [62]. Thus, a detailed systematic work-up to rule out both ocular and systemic associations is mandatory to prevent progression in every established case of aqueous deficiency DED [62]. An algorithmic approach, including a detailed history, clinical examination, serological evaluation, and additional specific and ancillary investigations, are required to unmask the underlying systemic associations in these patients [63].

\section{Medical Therapy}

Medical therapy, including ocular with or without systemic immunosuppressive therapy (IMT), in addition to supportive measures, such as ocular lubricants, are generally useful based on the etiology of DED [46]. Temporally limited causes of DED, such as Stevens-Johnson's syndrome (SJS) and chemical/thermal burns, are non-progressive, and the sequelae depend on the extent of damage occurring during the one-time insult during the acute phase. Amniotic membrane transplantation (AMT) with adequate medical therapy in the acute stage of SJS can hasten recovery and minimize sight-threatening complications of DED [64]. Likewise, timely and appropriate management of acute chemical burns with medical therapy and AMT can help limit associated ocular morbidity [65]. In progressive causes of DED generally seen with autoimmune pathologies, aggressive intensive IMT in acute phases followed by long term maintenance therapy can help limit disease progression. In addition to medical therapy, the use of scleral lenses such as prosthetic replacement of ocular surface ecosystem (PROSE) lenses helps relieve the symptoms, stabilizing the surface and visual rehabilitation of these patients [66].

Surgical Management

Some patients may have significant ocular morbidity that would need surgical interventions to either prevent or manage complications and for visual rehabilitation. Cataract 
surgery is safe and beneficial in patients with DED across various etiologies [67]. In the presence of a visually significant cataract, it is preferable to plan a cataract surgery as soon as possible, before significant keratopathy sets in. Corneal transplantation is not a preferred option for visual rehabilitation due to poor graft survival rates in these eyes with a hostile ocular surface environment $[68,69]$. Hence, it should be considered a last resort for tectonic stabilization of the globe if required and not for visual rehabilitation. Other techniques for tectonic stabilization of the globe, such as Tenon's patch graft, multi-layered AMT, cyanoacrylate tissue adhesive application, or corneal patch graft, should be preferred over tectonic penetrating keratoplasty when feasible [70-72]. Specialized surgeries, such as limbal stem cell transplantation [73] and Boston type I keratoprosthesis [74], can be undertaken for relatively wet eyes for visual rehabilitation. However, Boston type II keratoprosthesis (Kpro) [75], LVP Kpro [76], or modified osteo-odonto keratoprosthesis [77] are needed in very severe DED with end-stage ocular surface disease.

A combination of medical and surgical interventions followed by scleral lenses are generally needed in advanced cases of DED. Such multimodal approaches have been reported to change the natural course of the disease and limit ocular morbidity in cases with DED related to SJS $[78,79]$.

\section{Health Education}

It is essential to increase awareness among patients, medical and paramedical professionals, and general ophthalmologists about the potential visual rehabilitative measures available to improve the quality of life of patients with end-stage ocular surface disease. Most patients with advanced disease who have a potential for visual rehabilitation end up leading disability-adjusted life years (DALY) due to a lack of awareness or appropriate referral to centers offering specialized and advanced care for ocular surface disease. Advanced ocular surface surgical techniques, such as stem cell transplantation and keratoprosthesis surgery, can help visually rehabilitate these patients [72,74,75]. Apart from treating ocular ailments, consultation and counselling from mental health professionals is vital to deliver holistic care to these patients and effectively handle associated depression, anxiety, and sleep-related disorders [80]. Research has shown that subjective happiness was associated with lower reporting of symptoms of DED, despite the presence of objective signs and vice versa, highlighting the importance of positive psychological interventions in these patients [81]. An algorithmic approach to prevention of DED is described in Figure 2, and a summary of various measures of prevention is described in Figure 3.

\subsection{Quaternary Prevention}

This is a higher level of prevention where the action is taken to identify patients at risk for over-medicalization [81]. The primary objective of this level of prevention is to suggest ethically acceptable interventions to patients and protect them from new medical invasion. It targets the health care system as a whole, intending to reduce iatrogenesis and disease mongering. 


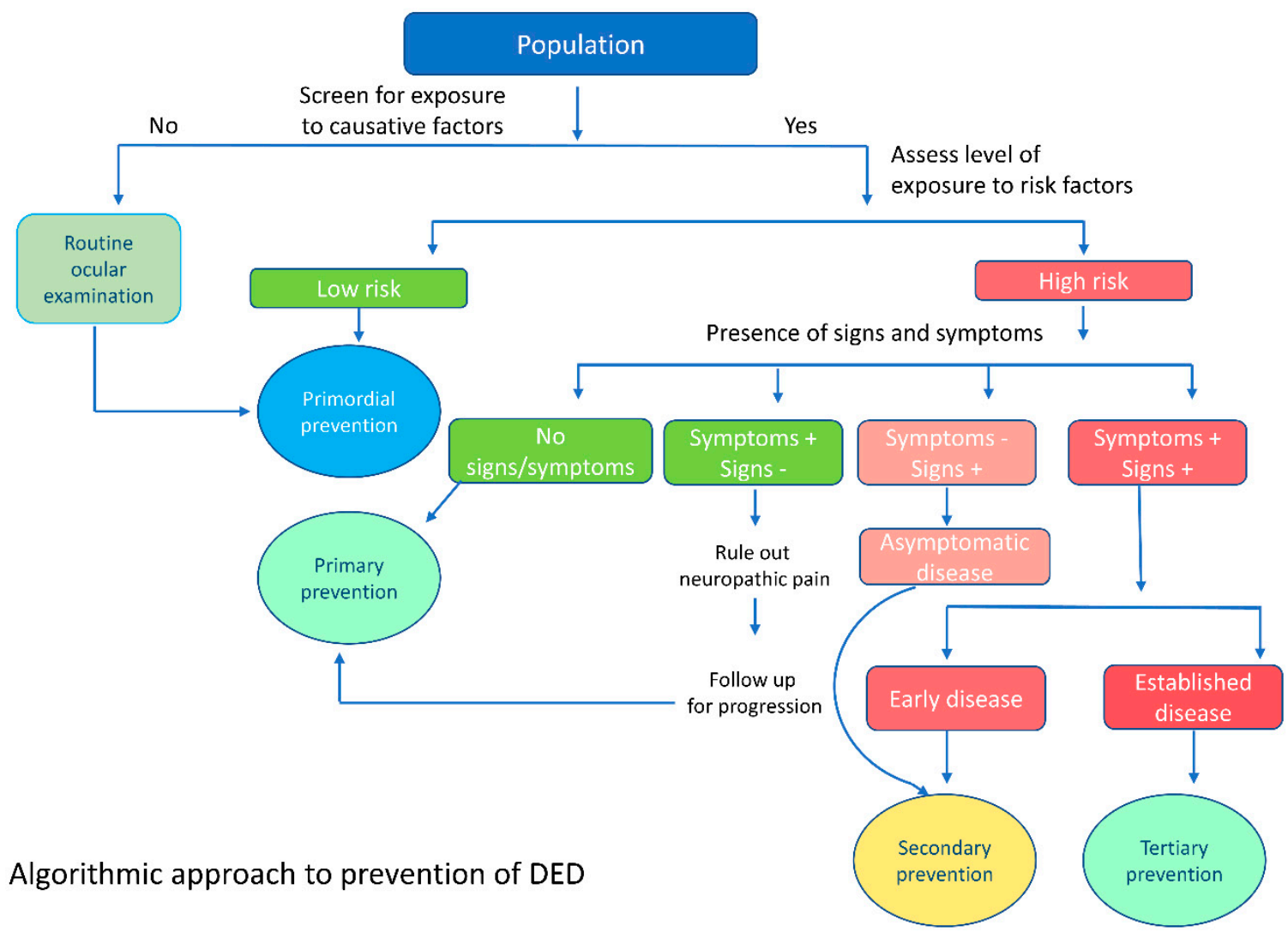

Figure 2. Algorithm for the prevention of dry eye disease: the figure depicts the approach to evaluating a patient with dry eye disease and the institution of various preventive strategies based on the clinical course and disease severity. The low-risk and high-risk stratification is based on the strength of the evidence present in the literature with regards to the association of a risk factor with DED, as stated in the Tear film and ocular surface society - dry eye workshop II (TFOS DEWS II) epidemiology report [2]. High risk includes risk factors such as age, female gender, connective tissue disorders, Sjogrens syndrome, VDU use, contact lens use, Bone marrow transplantation, and environmental factors. Low risk factors include post refractive surgery, allergic conjunctivitis, thyroid disease, psychiatric conditions, diabetes, and low fatty acid intake.

\section{Strategies for Quaternary Prevention}

DED can be caused iatrogenically while managing various ocular and systemic medical conditions related primarily to drug toxicity [28,82]. Additionally, over the counter availability of lubricants with preservatives at lower cost can lead to their long term, widespread use and subsequent ocular surface toxicity $[50,83,84]$. To ensure a dynamic balance between the risks and benefits of various treatment modalities offered for DED, it is essential to lay down strict technical criteria for medical interventions. Ethical requirements should be laid down carefully, and strict institutional control methods should be put in place in all health care organizations [82]. Systematization of medical care of patients and educating all health care workers on these protective measures can help protect citizens and patients from over-medicalization. It is vital for optometrists and general practitioners, who are the first-line healthcare personnel, to be aware of the entire spectrum of DED and the management strategies available $[85,86]$. Moreover, public policies and financing should be carried out to ensure compliance and uniformity across the country. 


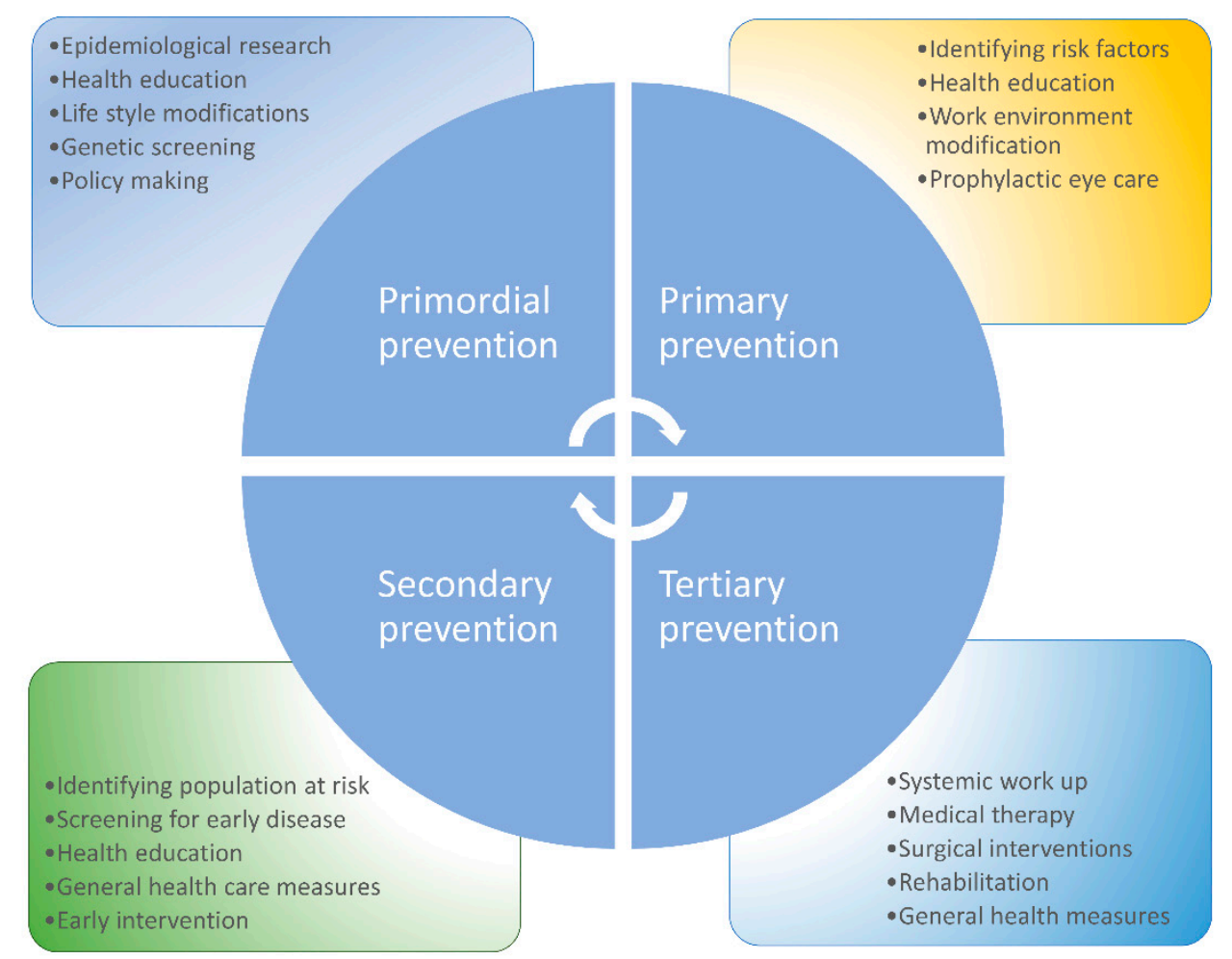

Figure 3. Summary of the various strategies for prevention of dry eye disease: this figure describes the numerous strategies for the prevention of DED at various levels of healthcare.

\section{Conclusions}

DED is an emerging disease with a significant economic and humanistic burden, and needs a strategic approach focusing on preventive measures to effectively tackle it. It is imperative for occupational physicians, general practitioners, general ophthalmologists, cornea, and ocular surface specialists to undertake risk factor management in addition to delivering conventional care to all their patients. Thus, the first step towards this would be undertaking risk assessment, i.e., watching out for the presence of risk factors of DED in all patients visiting our clinics irrespective of the presenting complaint. After assessing the risk, we need to institute appropriate preventive measures to effectively control the emergence, establishment, and progression of DED. With the millennial technological revolution and lifestyle trends accentuating the evolution of DED as a global health burden, a perfect synergy between curative and preventive measures is the only way to ameliorate the massive suffering associated with this disease.

Author Contributions: Conceptualization, S.B. and P.R.D.; methodology P.R.D. and S.B.; writing-original draft preparation, P.R.D. and S.B.; writing-review and editing, P.R.D., S.S.S., and S.B. All authors have read and agreed to the published version of the manuscript.

Funding: Intramural grant of Hyderabad Eye Research Foundation (HERF).

Institutional Review Board Statement: Not applicable.

Informed Consent Statement: Not applicable.

Data Availability Statement: Not applicable.

Conflicts of Interest: The authors declare no conflict of interest.

\section{References}

1. Craig, J.P.; Nichols, K.K.; Akpek, E.K.; Caffery, B.; Dua, H.S.; Joo, C.K.; Liu, Z.; Nelson, J.D.; Nichols, J.J.; Tsubota, K.; et al. TFOS DEWS II Definition and Classification Report. Ocul. Surf. 2017, 15, 276-283. [CrossRef] [PubMed] 
2. Stapleton, F.; Alves, M.; Bunya, V.Y.; Jalbert, I.; Lekhanont, K.; Malet, F.; Na, K.S.; Schaumberg, D.; Uchino, M.; Vehof, J.; et al. TFOS DEWS II Epidemiology Report. Ocul. Surf. 2017, 15, 334-365. [CrossRef] [PubMed]

3. Moon, J.H.; Kim, K.W.; Moon, N.J. Smartphone use is a risk factor for pediatric dry eye disease according to region and age: A case control study Pediatrics and Strabismus. BMC Ophthalmol. 2016, 16. [CrossRef] [PubMed]

4. Uchino, M.; Yokoi, N.; Uchino, Y.; Dogru, M.; Kawashima, M.; Komuro, A.; Sonomura, Y.; Kato, H.; Kinoshita, S.; Schaumberg, D.A.; et al. Prevalence of dry eye disease and its risk factors in visual display terminal users: The Osaka study. Am. J. Ophthalmol. 2013, 156. [CrossRef] [PubMed]

5. Geerling, G.; Liu, C.S.C.; Collin, J.R.O.; Dart, J.K.G. Costs and gains of complex procedures to rehabilitate end stage ocular surface disease. Br. J. Ophthalmol. 2002, 86, 1220-1221. [CrossRef]

6. Na, K.S.; Han, K.; Park, Y.G.; Na, C.; Joo, C.K. Depression, stress, quality of life, and dry eye disease in korean women: A population-based study. Cornea 2015, 34, 733-738. [CrossRef]

7. van der Vaart, R.; Weaver, M.A.; Lefebvre, C.; Davis, R.M. The association between dry eye disease and depression and anxiety in a large population-based study. Am. J. Ophthalmol. 2015, 159, 470-474. [CrossRef]

8. Dana, R.; Bradley, J.L.; Guerin, A.; Pivneva, I.; Stillman, I.Ö.; Evans, A.M.; Schaumberg, D.A. Estimated Prevalence and Incidence of Dry Eye Disease Based on Coding Analysis of a Large, All-age United States Health Care System. Am. J. Ophthalmol. 2019, 202, 47-54. [CrossRef]

9. Donthineni, P.R.; Kammari, P.; Shanbhag, S.S.; Singh, V.; Das, A.V.; Basu, S. Incidence, demographics, types and risk factors of dry eye disease in India: Electronic medical records driven big data analytics report I. Ocul. Surf. 2019. [CrossRef]

10. Bonita Beaglehole, R.R. Basic Epidemiology, 2nd ed.; World Health Organization: Geneva, Switzerland, 2006.

11. Tandon, R.; Vashist, P.; Gupta, N.; Gupta, V.; Sahay, P.; Deka, D.; Singh, S.; Vishwanath, K.; Murthy, G.V.S. Association of dry eye disease and sun exposure in geographically diverse adult ( $\geq 40$ years) populations of India: The SEED (sun exposure, environment and dry eye disease) study-Second report of the ICMR-EYE SEE study group. In The Ocular Surface; Elsevier Inc.: Amsterdam, The Netherlands, 2020; Volume 18, pp. 718-730.

12. Hanyuda, A.; Sawada, N.; Uchino, M.; Kawashima, M.; Yuki, K.; Tsubota, K.; Yamagishi, K.; Iso, H.; Yasuda, N.; Saito, I.; et al. Physical inactivity, prolonged sedentary behaviors, and use of visual display terminals as potential risk factors for dry eye disease: JPHC-NEXT study. Ocul. Surf. 2020, 18, 56-63. [CrossRef]

13. Lee, J.H.; Kim, S.J.; Byun, Y.S.; Lee, J.; Park, S.H.; Chung, S.H. The Association of Serum Vitamin D Level with the Severity of Dry Eye Parameters in Primary Sjögren Syndrome. Cornea 2020, 39, 702-705. [CrossRef] [PubMed]

14. Bhargava, R.; Kumar, P.; Phogat, H.; Kaur, A.; Kumar, M. Oral omega-3 fatty acids treatment in computer vision syndrome related dry eye. Contact Lens Anterior Eye 2015, 38, 206-210. [CrossRef] [PubMed]

15. Donthineni, P.R.; Das, A.V.; Basu, S. Dry eye disease in children and adolescents in India. Ocul. Surf. 2020, 18, 777-782. [CrossRef] [PubMed]

16. Sommer, A.; Emran, N. Tear production in vitamin a-responsive xerophthalmia. Am. J. Ophthalmol. 1982, 93, 84-87. [CrossRef]

17. Bron, A.J.; de Paiva, C.S.; Chauhan, S.K.; Bonini, S.; Gabison, E.E.; Jain, S.; Knop, E.; Markoulli, M.; Ogawa, Y.; Perez, V.; et al. TFOS DEWS II pathophysiology report. Ocul. Surf. 2017, 15, 438-510. [CrossRef] [PubMed]

18. Hwang, J.S.; Lee, Y.P.; Shin, Y.J. Vitamin D enhances the efficacy of topical artificial tears in patients with dry eye disease. Cornea 2019, 38, 304-310. [CrossRef] [PubMed]

19. Kawashima, M.; Sano, K.; Takechi, S.; Tsubota, K. Impact of lifestyle intervention on dry eye disease in office workers: A randomized controlled trial. J. Occup. Health 2018, 60, 281-288. [CrossRef] [PubMed]

20. Molina-Leyva, I.; Molina-Leyva, A.; Bueno-Cavanillas, A. Efficacy of nutritional supplementation with omega-3 and omega-6 fatty acids in dry eye syndrome: A systematic review of randomized clinical trials. Acta Ophthalmol. 2017, 95, e677-e685. [CrossRef] [PubMed]

21. Deinema, L.A.; Vingrys, A.J.; Wong, C.Y.; Jackson, D.C.; Chinnery, H.R.; Downie, L.E. A Randomized, Double-Masked, PlaceboControlled Clinical Trial of Two Forms of Omega-3 Supplements for Treating Dry Eye Disease. Ophthalmology $2017,124,43-52$. [CrossRef] [PubMed]

22. Macsai, M.S. The role of omega-3 dietary supplementation in blepharitis and meibomian gland dysfunction (an AOS thesis). Trans Am Ophthalmol Soc. 2008, 106, 336-356. [PubMed]

23. Dry Eye Assessment and Management Study Research Group. n-3 Fatty Acid Supplementation for the Treatment of Dry Eye Disease. N. Engl. J. Med. 2018, 378, 1681-1690. [CrossRef] [PubMed]

24. Hussain, M.; Shtein, R.M.; Pistilli, M.; Maguire, M.G.; Oydanich, M.; Asbell, P.A. The Dry Eye Assessment and Management (DREAM) extension study-A randomized clinical trial of withdrawal of supplementation with omega-3 fatty acid in patients with dry eye disease. Ocul. Surf. 2020, 18, 47-55. [CrossRef] [PubMed]

25. Sano, K.; Kawashima, M.; Takechi, S.; Mimura, M.; Tsubota, K. Exercise program improved subjective dry eye symptoms for office workers. Clin. Ophthalmol. 2018, 12, 307-311. [CrossRef] [PubMed]

26. Bazeer, S.; Jansonius, N.; Snieder, H.; Hammond, C.; Vehof, J. The relationship between occupation and dry eye. Ocul. Surf. 2019, 17, 484-490. [CrossRef] [PubMed]

27. Jung, S.J.; Mehta, J.S.; Tong, L. Effects of environment pollution on the ocular surface. Ocul. Surf. 2018, 16, 198-205. [CrossRef]

28. Gomes, J.A.P.; Azar, D.T.; Baudouin, C.; Efron, N.; Hirayama, M.; Horwath-Winter, J.; Kim, T.; Mehta, J.S.; Messmer, E.M.; Pepose, J.S.; et al. TFOS DEWS II iatrogenic report. Ocul. Surf. 2017, 15, 511-538. [CrossRef] 
29. Portello, J.K.; Rosenfield, M.; Chu, C.A. Blink rate, incomplete blinks and computer vision syndrome. Optom. Vis. Sci. 2013, 90, 482-487. [CrossRef]

30. Chu, C.A.; Rosenfield, M.; Portello, J.K. Blink patterns: Reading from a computer screen versus hard copy. Optom. Vis. Sci. 2014, 91, 297-302. [CrossRef]

31. Cardona, G.; García, C.; Serés, C.; Vilaseca, M.; Gispets, J. Blink rate, blink amplitude, and tear film integrity during dynamic visual display terminal tasks. Curr. Eye Res. 2011, 36, 190-197. [CrossRef]

32. Blehm, C.; Vishnu, S.; Khattak, A.; Mitra, S.; Yee, R.W. Computer vision syndrome: A review. Surv. Ophthalmol. 2005, 50, 253-262. [CrossRef]

33. Mackie, I.A.; Seal, D.V.; Pescod, J.M. Beta-adrenergic receptor blocking drugs: Tear lysozyme and immunological screening for adverse reaction. Br. J. Ophthalmol. 1977, 61, 354-359. [CrossRef] [PubMed]

34. Inomata, T.; Iwagami, M.; Nakamura, M.; Shiang, T.; Yoshimura, Y.; Fujimoto, K.; Okumura, Y.; Eguchi, A.; Iwata, N.; Miura, M.; et al. Characteristics and Risk Factors Associated with Diagnosed and Undiagnosed Symptomatic Dry Eye Using a Smartphone Application. JAMA Ophthalmol. 2020, 138, 58-68. [CrossRef] [PubMed]

35. Amick, B.C.; Menéndez, C.C.; Bazzani, L.; Robertson, M.; DeRango, K.; Rooney, T.; Moore, A. A field intervention examining the impact of an office ergonomics training and a highly adjustable chair on visual symptoms in a public sector organization. Appl. Ergon. 2012, 43, 625-631. [CrossRef] [PubMed]

36. Nichols, K.K.; Bacharach, J.; Holland, E.; Kislan, T.; Shettle, L.; Lunacsek, O.; Lennert, B.; Burk, C.; Patel, V. Impact of dry eye disease on work productivity, and patients' Satisfaction with Over-The-Counter dry eye treatments. Investig. Ophthalmol. Vis. Sci. 2016, 57, 2975-2982. [CrossRef] [PubMed]

37. Psihogios, J.P.; Sommerich, C.M.; Mirka, G.A.; Moon, S.D. A field evaluation of monitor placement effects in VDT users. Appl. Ergon. 2001, 32, 313-325. [CrossRef]

38. Jaschinski, W.; Heuer, H.; Kylian, H. Preferred position of visual displays relative to the eyes: A field study of visual strain and individual differences. Ergonomics 1998, 41, 1034-1049. [CrossRef] [PubMed]

39. Kaido, M.; Toda, I.; Oobayashi, T.; Kawashima, M.; Katada, Y.; Tsubota, K. Reducing short-wavelength blue light in dry eye patients with unstable tear film improves performance on tests of visual acuity. PLoS ONE 2016, 11, 152936. [CrossRef]

40. Cheu, R.A. Good vision at work. Occup. Health Saf. (WacoTex.) 1998, 67, 20-24.

41. Nosch, D.S.; Foppa, C.; Tóth, M.; Joos, R.E. Blink animation software to improve blinking and dry eye symptoms. Optom. Vis. Sci. 2015, 92, e310-e315. [CrossRef]

42. Jalbert, I. Diet, nutraceuticals and the tear film. Exp. Eye Res. 2013, 117, 138-146. [CrossRef]

43. Blades, K.J.; Patel, S.; Aidoo, K.E. Oral antioxidant therapy for marginal dry eye. Eur. J. Clin. Nutr. 2001, 55, 589-597. [CrossRef] [PubMed]

44. Patel, S.; Plaskow, J.; Ferrier, C. The influence of vitamins and trace element supplements on the stability of the pre-corneal tear film. Acta Ophthalmol. 1993, 71, 825-829. [CrossRef] [PubMed]

45. Fenga, C.; Aragona, P.; di Nola, C.; Spinella, R. Comparison of ocular surface disease index and tear osmolarity as markers of ocular surface dysfunction in video terminal display workers. Am. J. Ophthalmol. 2014, 158. [CrossRef] [PubMed]

46. Jones, L.; Downie, L.E.; Korb, D.; Benitez-del-Castillo, J.M.; Dana, R.; Deng, S.X.; Dong, P.N.; Geerling, G.; Hida, R.Y.; Liu, Y.; et al. TFOS DEWS II Management and Therapy Report. Ocul. Surf. 2017, 15, 575-628. [CrossRef]

47. Wang, M.T.M.; Chan, E.; Ea, L.; Kam, C.; Lu, Y.; Misra, S.L.; Craig, J.P. Randomized Trial of Desktop Humidifier for Dry Eye Relief in Computer Users. Optom. Vis. Sci. 2017, 94, 1052-1057. [CrossRef]

48. Lee, H.; Kim, M.; Park, S.Y.; Kim, E.K.; Seo, K.Y.; Kim, T.I. Mechanical meibomian gland squeezing combined with eyelid scrubs and warm compresses for the treatment of meibomian gland dysfunction. Clin. Exp. Optom. 2017, 100, 598-602. [CrossRef]

49. Hirayama, M.; Murat, D.; Liu, Y.; Kojima, T.; Kawakita, T.; Tsubota, K. Efficacy of a novel moist cool air device in office workers with dry eye disease. Acta Ophthalmol. 2013, 91, 756-762. [CrossRef]

50. Pucker, A.D.; Ng, S.M.; Nichols, J.J. Over the counter (OTC) artificial tear drops for dry eye syndrome. Cochrane Database Syst. Rev. 2016, 2016. [CrossRef]

51. Sheppard, J.D.; Donnenfeld, E.D.; Holland, E.J.; Slonim, C.B.; Solomon, R.; Solomon, K.D.; McDonald, M.B.; Perry, H.D.; Lane, S.S.; Pflugfelder, S.C.; et al. Effect of Loteprednol Etabonate $0.5 \%$ on Initiation of Dry Eye Treatment with Topical Cyclosporine 0.05\%. Eye Contact Lens: Sci. Clin. Pract. 2014, 40, 289-296. [CrossRef]

52. Byun, Y.; Kim, T.; Kwon, S.M.; Seo, K.Y.; Kim, S.W.; Kim, E.K.; Park, W.C. Efficacy of Combined 0.05\% Cyclosporine and 1\% Methylprednisolone Treatment for Chronic Dry Eye. Cornea 2012, 31, 509-513. [CrossRef]

53. Chen, W.; Zhang, X.; Liu, M.; Zhang, J.; Ye, Y.; Lin, Y.; Luyckx, J.; Qu, J. Trehalose protects against ocular surface disorders in experimental murine dry eye through suppression of apoptosis. Exp. Eye Res. 2009, 89, 311-318. [CrossRef] [PubMed]

54. Lee, S.Y.; Tong, L. Lipid-containing lubricants for dry eye: A systematic review. Optom. Vis. Sci. 2012, 89, 1654-1661. [CrossRef] [PubMed]

55. Shigeyasu, C.; Hirano, S.; Akune, Y.; Yamada, M. Diquafosol Tetrasodium Increases the Concentration of Mucin-like Substances in Tears of Healthy Human Subjects. Curr. Eye Res. 2015, 40, 878-883. [CrossRef] [PubMed]

56. Kinoshita, S.; Awamura, S.; Nakamichi, N.; Suzuki, H.; Oshiden, K.; Yokoi, N. A multicenter, open-label, 52-week study of 2\% rebamipide (OPC-12759) ophthalmic suspension in patients with dry eye. Am. J. Ophthalmol. 2014, 157, 576-583.e1. [CrossRef] 
57. Itakura, H.; Kashima, T.; Itakura, M.; Akiyama, H.; Kishi, S. Clinical Ophthalmology Dovepress topical rebamipide improves lid wiper epitheliopathy. Clin. Ophthalmol. (Auckl. N.Z.) 2013, 7, 2137. [CrossRef]

58. Holland, E.J.; Luchs, J.; Karpecki, P.M.; Nichols, K.K.; Jackson, M.A.; Sall, K.; Tauber, J.; Roy, M.; Raychaudhuri, A.; Shojaei, A. Lifitegrast for the Treatment of Dry Eye Disease: Results of a Phase III, Randomized, Double-Masked, Placebo-Controlled Trial (OPUS-3). Ophthalmology 2017, 124, 53-60. [CrossRef]

59. Ervin, A.M.; Law, A.; Pucker, A.D. Punctal occlusion for dry eye syndrome. Cochrane Database Syst. Rev. 2017, 2017. [CrossRef]

60. Yazici, B.; Bilge, A.D.; Naqadan, F. Lacrimal Punctal Occlusion with Conjunctival Flap. Ophthalmic Plast. Reconstr. Surg. 2015, 31, 300-302. [CrossRef]

61. Putterman, A.M. Canaliculectomy in the treatment of keratitis sicca. Ophthalmic Surg. 1991, 22, 478-480. [CrossRef]

62. Wolffsohn, J.S.; Arita, R.; Chalmers, R.; Djalilian, A.; Dogru, M.; Dumbleton, K.; Gupta, P.K.; Karpecki, P.; Lazreg, S.; Pult, H.; et al TFOS DEWS II Diagnostic Methodology report. Ocul. Surf. 2017, 15, 539-574. [CrossRef]

63. Vazirani, J.; Donthineni, P.; Goel, S.; Sane, S.; Mahuvakar, S.; Narang, P.; Shanbhag, S.; Basu, S. Chronic cicatrizing conjunctivitis: A review of the differential diagnosis and an algorithmic approach to management. Indian J. Ophthalmol. 2020, 68, 2349. [CrossRef] [PubMed]

64. Shanbhag, S.S.; Rashad, R.; Chodosh, J.; Saeed, H.N. Long-Term Effect of a Treatment Protocol for Acute Ocular Involvement in Stevens-Johnson Syndrome/Toxic Epidermal Necrolysis. Am. J. Ophthalmol. 2019, 208, 331-341. [CrossRef] [PubMed]

65. Westekemper, H.; Figueiredo, F.C.; Siah, W.F.; Wagner, N.; Steuhl, K.P.; Meller, D. Clinical outcomes of amniotic membrane transplantation in the management of acute ocular chemical injury. Br. J. Ophthalmol. 2017, 101, 103-107. [CrossRef] [PubMed]

66. Bavinger, J.C.; DeLoss, K.; Mian, S.I. Scleral lens use in dry eye syndrome. Curr. Opin. Ophthalmol. 2015, 26, 319-324. [CrossRef] [PubMed]

67. Donthineni, P.R.; Das, A.V.; Shanbhag, S.S.; Basu, S. Cataract Surgery in Dry Eye Disease: Visual Outcomes and Complications. Front. Med. 2020, 7. [CrossRef]

68. Tugal-Tutkun, I.; Akova, Y.A.; Foster, C.S. Penetrating Keratoplasty in Cicatrizing Conjunctival Diseases. Ophthalmology 1995, 102, 576-585. [CrossRef]

69. Palay, D.A.; Stulting, R.D.; Waring, G.O.; Wilson, L.A. Penetrating Keratoplasty in Patients with Rheumatoid Arthritis. Ophthalmology 1992, 99, 622-627. [CrossRef]

70. Deshmukh, R.; Stevenson, L.; Vajpayee, R. Management of corneal perforations: An update. Indian J. Ophthalmol. 2020, 68, 7. [CrossRef]

71. Sharma, N.; Singhal, D.; Maharana, P.K.; Vajpayee, R.B. Tuck-In Tenon Patch Graft in Corneal Perforation. Cornea 2019, 38, 951-954. [CrossRef]

72. Korah, S.; Selvin, S.S.T.; Pradhan, Z.S.; Jacob, P.; Kuriakose, T. Tenons Patch Graft in the Management of Large Corneal Perforations. Cornea 2016, 35, 696-699. [CrossRef]

73. Shanbhag, S.; Patel, C.; Goyal, R.; Donthineni, P.; Singh, V.; Basu, S. Simple limbal epithelial transplantation (SLET): Review of indications, surgical technique, mechanism, outcomes, limitations, and impact. Indian J. Ophthalmol. 2019, 67, 1265-1277. [PubMed]

74. Basu, S.; Serna-Ojeda, J.C.; Senthil, S.; Pappuru, R.R.; Bagga, B.; Sangwan, V. The Aurolab Keratoprosthesis (KPro) versus the Boston Type I Kpro: 5-year Clinical Outcomes in 134 Cases of Bilateral Corneal Blindness. Am. J. Ophthalmol. 2019, 205, 175-183. [CrossRef] [PubMed]

75. Lee, R.; Khoueir, Z.; Tsikata, E.; Chodosh, J.; Dohlman, C.H.; Chen, T.C. Long-term Visual Outcomes and Complications of Boston Keratoprosthesis Type II Implantation. In The Ophthalmology; Elsevier Inc.: Amsterdam, The Netherlands, 2017; Volume 124, pp. 27-35.

76. Basu, S.; Nagpal, R.; Serna-Ojeda, J.C.; Bhalekar, S.; Bagga, B.; Sangwan, V. LVP keratoprosthesis: Anatomical and functional outcomes in bilateral end-stage corneal blindness. Br. J. Ophthalmol. 2019, 103, 592-598. [CrossRef] [PubMed]

77. Falcinelli, G.; Falsini, B.; Taloni, M.; Colliardo, P.; Falcinelli, G. Modified osteo-odonto-keratoprosthesis for treatment of corneal blindness: Long-term anatomical and functional outcomes in 181 cases. Arch. Ophthalmol. 2005, 123, 1319-1329. [CrossRef]

78. Shanbhag, S.S.; Shah, S.; Singh, M.; Bahuguna, C.; Donthineni, P.R.; Basu, S. Lid-Related Keratopathy in Stevens-Johnson Syndrome: Natural Course and Impact of Therapeutic Interventions in Children and Adults. Am. J. Ophthalmol. 2020. [CrossRef]

79. Basu, S.; Shanbhag, S.S.; Gokani, A.; Kedar, R.; Bahuguna, C.; Sangwan, V.S. Chronic Ocular Sequelae of Stevens-Johnson Syndrome in Children: Long-term Impact of Appropriate Therapy on Natural History of Disease. Am. J. Ophthalmol. 2018, 189, 17-28. [CrossRef]

80. Kawashima, M.; Uchino, M.; Yokoi, N.; Uchino, Y.; Dogru, M.; Komuro, A.; Sonomura, Y.; Kato, H.; Kinoshita, S.; Mimura, M.; et al. Associations between Subjective Happiness and Dry Eye Disease: A New Perspective from the Osaka Study. PLoS ONE 2015, 10, e0123299. [CrossRef]

81. Martins, C.; Godycki-Cwirko, M.; Heleno, B.; Brodersen, J. Quaternary prevention: Reviewing the concept. Eur. J. Gen. Pract. 2018, 24, 106-111. [CrossRef]

82. Martins, C.; Godycki-Cwirko, M.; Heleno, B.; Brodersen, J. Quaternary prevention: An evidence-based concept aiming to protect patients from medical harm. Br. J. Gen. Pract. 2019, 69, 614-615. [CrossRef]

83. Baudouin, C.; Labbé, A.; Liang, H.; Pauly, A.; Brignole-Baudouin, F. Preservatives in eyedrops: The good, the bad and the ugly. Prog. Retin. Eye Res. 2010, 29, 312-334. [CrossRef] 
84. Dutescu, R.M.; Panfil, C.; Schrage, N. Comparison of the effects of various lubricant eye drops on the in vitro rabbit corneal healing and toxicity. Exp. Toxicol. Pathol. 2017, 69, 123-129. [CrossRef] [PubMed]

85. Downie, L.E.; Keller, P.R.; Vingrys, A.J. An evidence-based analysis of Australian optometrists' dry eye practices. Optom. Vis. Sci. 2013, 90, 1385-1395. [CrossRef] [PubMed]

86. Mayer, H. Good expert knowledge, small scope. Work 2014, 47, 353-364. [CrossRef] [PubMed] 